\title{
PAK5 promotes the migration and invasion of cervical cancer cells by phosphorylating SATB1
}

\author{
Fu-Chun Huo ${ }^{1,2} \cdot$ Yao-Jie $\mathrm{Pan}^{3} \cdot$ Tong-Tong $\mathrm{Li}^{1} \cdot$ Jie $\mathrm{Mou}^{4} \cdot$ Dong-Sheng Pei ${ }^{1,2}$
}

Received: 1 March 2018 / Revised: 8 July 2018 / Accepted: 16 July 2018 / Published online: 6 August 2018

(c) ADMC Associazione Differenziamento e Morte Cellulare 2018

\begin{abstract}
p21-activated kinase 5 (PAK5) is involved in several oncogenic signaling pathways and its amplification or overexpression has been found in various types of cancer; however, the pathophysiologic role of PAK5 in cervical cancer (CC) remains elusive. This study aims to elucidate the effects of PAK5 on CC metastasis and its specific regulation mechanism. We performed western blotting and immunohistochemistry (IHC) analysis and found that the expression levels of PAK5 were significantly upregulated in CC cells and tissues. In addition, statistical analysis via IHC showed that increased PAK5 significantly correlated with CC progression. $\mathrm{Mn}^{2+}$-Phos-tag SDS-PAGE, western blotting, immunofluorescence and dual luciferase reporter assays were utilized to determine the involvement of SATB1 in PAK5-mediated epithelial-mesenchymal transition (EMT). We found that PAK5-mediated special AT-rich binding protein-1 (SATB1) phosphorylation on Ser47 initiated EMT cascade and promoted migration and invasion of CC cells. Furthermore, overexpression of PAK5 induced lung metastasis of CC cells in xenograft modes. Taken together, we conclude that PAK5 is a novel prognostic indicator and plays an important role in the $\mathrm{CC}$ metastasis.
\end{abstract}

\section{Introduction}

Cervical cancer (CC) is one of the most common gynecology tumors and the second leading cause of cancer deaths among women in the world [1], with over 500,000

These authors contributed equally: Fu-Chun Huo, Yao-Jie Pan

\section{Edited by: D. Aberdam}

Jie Mou

mou.jie@126.com

$\triangle$ Dong-Sheng Pei

dspei@xzhmu.edu.cn

1 Department of pathology, Xuzhou Medical University, Xuzhou 221004, China

2 Jiangsu Key Laboratory of Biological Cancer Therapy, Xuzhou Medical University, Xuzhou 221002, China

3 Department of Oncology, The Affiliated Yancheng Hospital of Medicine School of Southeast University, Yancheng 224001, China

4 School of Pharmacy, Xuzhou Medical University, Xuzhou 221004, China new diagnosed cases and 260,000 deaths per year [2]. Tumor invasion and distant metastasis are the main causes for treatment failure and death in cancer patients, particularly in CC [3, 4]. Previous studies suggested that epithelial-mesenchymal transition (EMT) stimulated migration and invasion of tumor cells exerts a powerful effect on the process of occurrence, development, invasion, metastasis, and drug resistance of CC [4, 5]. Pelvic lymph node metastasis (LNM) of CC is dismissed as the most significant factor among the numerous high risks leading to unfavorable prognosis for postoperative patients [6]. Fiveyear survival rate of CC patients is reduced by $20-30 \%$ in the presence of LNM [7]. Therefore, there is an unmet clinical need to identify reliable biomarkers and improve therapeutic strategies for $\mathrm{CC}$ patients.

p21-activated kinases (PAKs) are highly conserved serine/threonine kinases family and are divided into two subfamilies: group I (PAK1, 2, and 3) and group II (PAK4, 5, and 6) [8, 9]. Unlike other group II PAK, PAK5 contains an autoinhibitory domain that binds with Cdc42-GTP and regulates its activity [10]. PAK5 was initially discovered in neuronal tissue [11], with high expression in the cerebellum, cerebral cortex, and olfactory bulb [9]. Subsequently, it was also detected in the pancreas [11]. Signaling pathways of PAK5 control a variety of cellular processes 
including neuronal outgrowth, cytoskeleton organization and cell proliferation, migration and invasion [10]. Earlier functional studies of PAK5 mainly concentrated in nervous system and suggested that PAK5 facilitates filopodium formation, neurite development, and regeneration of axon in NIE-115 cells [11]. Recently, PAK5 was identified as an oncogene in multiple human malignancies [10], such as colon cancer [12], ovarian cancer [13], osteosarcoma [14], hepatocellular carcinoma [15], breast cancer, and glioma $[16,17]$. However, the molecular mechanisms for PAK5 in $\mathrm{CC}$ progression remain to be fully elucidated.

Special AT-rich binding protein-1 (SATB1) is a tissue specific DNA-binding protein of nuclear matrix attachment region (MAR). Under physiological conditions, SATB1 predominantly expresses in the thymus, as well as bone marrow and nervous tissues; however, its expression is barely detectable in other tissues [18]. SATB1, as a genome organizer altering more than 1000 genes, specifically regulates temporal and spatial expression of multiple genes via identifying and combining the MAR [19, 20], which is accompanied by recruiting specific chromatin remodeling complexes to its anchorage sites and orchestrating chromatin architecture into loops [21]. In recent years, accumulating data have concluded that up-regulation of SATB1 is observed in many types of cancer, such as cutaneous malignant melanoma [22], prostate cancer [23], nasopharyngeal carcinoma [24], breast cancer and epithelial ovarian cancer [25, 26]. Functional profiling of genes revealed that the underlying mechanisms for SATB1 and chromatin modification affect cellular adhesive molecules and EMT [23].

In the current study, we analyzed PAK5 levels in CC tissues and cell lines and explored the expression relationships of PAK5 with clinicopathological characteristics using immunohistochemistry (IHC) staining. We found that PAK5 positively correlates with the aggressive phenotype of CC. In addition, PAK5 alters the expression of EMT markers and promotes invasion and metastasis of CC cells through phosphorylating SATB1 on Ser47. Our data provided a profound understanding of novel PAK5-SATB1 signaling in promoting $\mathrm{CC}$ invasion and metastasis.

\section{Materials and methods}

\section{Ethics statement}

All experiments involving human participants were approved by the Review Board of the Affiliated Hospital of Xuzhou Medical University. All patients provided a written informed consent prior to the study. Animal experiments were performed in strict accordance with the protocols approved by the Institutional Animal Care and Use Committee of Xuzhou Medical University.

\section{Patients and specimens}

We collected tissue specimens, which included 70 normal cervical tissues, 64 cervical intraepithelial neoplasms (CINs) and 163 CCs from the Department of Gynecology and Obstetrics, the Affliated Hospital of Xuzhou Medical University. Patients with CC received laparoscopic radical hysterectomy and pelvic lymphadenectomy. All CCs were staged in accordance with the criteria established by the International Federation of Gynecology and Obstetrics (FIGO). Detailed clinical information of specimen was recorded accurately and completely. All the CC patients were termly followed up for 4 months to 81 months to evaluate the postoperative survival.

\section{IHC staining and evaluation}

Paraffin-embedded cervical tissues were sectioned at $4 \mu \mathrm{m}$ thick. After being baked at $60^{\circ} \mathrm{C}$ for $2 \mathrm{~h}$, the tissue sections were deparaffinized with dimethylbenzene and rehydrated in different concentrations of alcohol. For retrieving antigen, the slides were heated at $95^{\circ} \mathrm{C}$ in $0.01 \mathrm{M}$ citrate buffer $(\mathrm{pH}$ $=6.0$ ), and $3 \%$ hydrogen peroxide was used to quench peroxidase activity for $20 \mathrm{~min}$. To avoid nonspecific staining, the sections were treated with normal goat serum, followed by incubation overnight with anti-PAK5 antibody (1:100 dilution; Abcam, Cambridge, MA, USA), antiphospho SATB1 Ser47 (1:100 dilution, Bioss, Beijing, China) and anti-E-cadherin (1:50 dilution, Abcam) at $4{ }^{\circ} \mathrm{C}$. After being rinsed with phosphate buffered saline (PBS), the sections were incubated with a secondary antibody for $1 \mathrm{~h}$ and stained with 3, 3'-diaminobenzidine (DAB; Zhongshan biotech, Beijing, China). After hematoxylin counterstain was completed, all the sections were dehydrated and sealed.

Two experienced pathologists independently evaluated the percentage of positive tumor cells and its staining intensity. The values of PAK5 staining intensity were assigned as follows: 0 (negative), 1 (weak), 2 (moderate) and 3 (strong). The values of percentage of positive tumor cells were scored as follows: (1) $(0-25 \%)$, (2) $(26-50 \%)$, (3) $(51-75 \%)$ and (4) (76-100\%). The immunoreactive score (IRS) of each section was calculated by the products of the staining intensity and percentage of tumor cells. According to the IRS, staining patterns were divided into three classes: weak (IRS: 0-3), moderate (IRS: 4-6), and strong (IRS: 8-12).

\section{Cell culture}

Human CC cells SiHa, Caski, C33A, MS751 and HeLa were acquired from the Institute of Biochemistry and Cell Biology at the Chinese Academy of Sciences (Shanghai, China). Normal cervical epithelial cells (NCECs) were obtained from endocervical biopsy of patients who had no 
underlying endocervical pathology and malignant lesions and had never been subjected to radiotherapy and (or) chemotherapy before operations. C33A, HeLa, and SiHa cells were cultured in DMEM (Gibco, Grand Island, NY, USA), and MS751 and CaSki cells were cultured in RPMI 1640 (Gibco). NCECs were cultured in medium mixed according to the proportion of 75\% DMEM (Gibco): $25 \%$ MCDB-105 (Sigma, St Louis, MO, USA) in volume [27]. Media were supplemented with 10\% FBS (Gibco) and 1\% antibiotics. All cells were maintained at $37{ }^{\circ} \mathrm{C}$ in a humidified chamber with $5 \% \mathrm{CO}_{2}$.

\section{Transfection and generation of stable cell lines}

siRNAs were designed and synthesized by GenePharma (Shanghai, China). HeLa and SiHa cells were transfected with the siRNA control (siCtrl), siRNA PAK5 (siPAK5) and siRNA SATB1 (siSATB1) using siLentFect ${ }^{\mathrm{TM}}$ Lipid Reagent (Bio-Rad, Hercules, CA, USA) following the manufacturer's protocol. The plasmids of pcDNA3.1-control, pcDNA3.1-SATB1, pcDNA3.1-SATB1 Ser47A, pcDNA3.1-SATB1 Ser451A, pcDNA3.1-SATB1 Ser557A, and pcDNA3.1-PAK5 (GenePharma) were transiently transfected into cells using the X-tremeGENE HP DNA Transfection Reagent (Roche, Indianapolis, IN, USA). After $24 \mathrm{~h}$ or $48 \mathrm{~h}$ of transfection, cells were harvested for the following experiments. Stable cell lines were established by the infection with PAK5-lentivirus (LV-PAK5) and controllentivirus (LV-Ctrl, GenePharma) and were selected with 2 $\mu \mathrm{g} / \mathrm{ml}$ puromycin (Vicmed, Xuzhou, China) for 15 days.

\section{Protein isolation and western blotting}

Protein samples were harvested from cell lysates and the protein concentration was determined by bicinchoninic acid kit (BCA, Beyotime Biotechnology, Beijing, China). The proteins were separated by $10 \%$ SDS-PAGE and transferred to nitrocellulose membrane. The membrane was blocked with 5\% nonfat milk in PBS for $1 \mathrm{~h}$ at room temperature and then incubated overnight at $4{ }^{\circ} \mathrm{C}$ with primary antibody: antiPAK5, anti-SATB1, anti-Slug, anti-E-Cadherin, anti-N-Cadherin, anti-Vimentin, anti-Twist, anti-Fibronectin (Abcam), anti-phospho SATB1 Ser47 (Bioss), anti-GAPDH (Zhongshan biotech). After been washed with PBS, the membrane was probed with corresponding HRP secondary antibodies for $2 \mathrm{~h}$ at room temperature. Finally, the protein signals were detected semiquantitatively with Tanon ${ }^{\mathrm{TM}}$ High-sig ECL Western Blotting Substrate (Tanon, Shanghai, China).

\section{Cell proliferation assay}

Cell proliferation was evaluated using the Cell Counting Kit-8 (CCK-8) kit (Vicmed). Transfected HeLa and SiHa cells $\left(3 \times 10^{3}\right)$ were seeded into 96-well plates (Corning Incorporated, Corning, NY, USA). $10 \mu \mathrm{l}$ of CCK-8 solution was then added to each well containing $100 \mu$ of serum-free medium at the indicated time points. The cells were incubated for $2 \mathrm{~h}$ at $37^{\circ} \mathrm{C}$. Degree of cell proliferation was measured by the increase in absorbance at $450 \mathrm{~nm}$. All assays were repeated three times.

\section{Colony formation assay}

Transfected HeLa and SiHa cells were plated in 6-well plates (Corning Incorporated) at a density of 300 cells per well. After the 2-week incubation, we removed the medium and stained the cells with Giemsa solution for $30 \mathrm{~min}$. Visible colonies (more than 50 cells) were counted under a light microscopy. All assays were repeated three times.

\section{Transwell invasion and migration assay}

Cell invasion and migration assays were performed as previously described [28]. For invasion assay, transwell chambers (BD Bioscience, San Jose, CA, USA) containing $8 \mu \mathrm{m}$ pores were coated with Matrigel in the upper chamber. Briefly, $100 \mu$ of cell suspension $\left(1 \times 10^{5}\right.$ cells $)$ of serumfree medium was plated in the lower chamber, medium with $10 \%$ FBS added to the lower chamber. After incubating 14 $\mathrm{h}$ for migration and $20 \mathrm{~h}$ for invasion, we removed the cells of upper chamber and then stained the invasive cells using Giemsa solution. The CC cells of migration and invasion were calculated and photographed under a light microscopy. All assays were repeated three times.

\section{Wound healing assay}

The transfected HeLa and SiHa cells were seeded in 6-well plates (Corning Incorporated). When cell culture reached about 95\% confluence, the cell monolayer was slowly scratched with a sterile $200 \mu \mathrm{l}$ pipette tip. We washed the well with fresh medium to remove cellular debris and cultured cells again. The wound was imaged at 0 and $24 \mathrm{~h}$. All assays were repeated three times.

\section{Immunofluorescence}

Briefly, transfected HeLa and SiHa cells were cultured on glass coverslips in 6-well plates (Corning Incorporated). Cells were fixed in cold $4 \%$ paraformaldehyde for $20 \mathrm{~min}$ at room temperature and were then permeabilized with $0.3 \%$ Triton-X100 for 15 min. After being blocked in 5\% BSA for $30 \mathrm{~min}$, the cells were incubated with anti-phospho SATB1 Ser47 antibody (dilution 1: 100, Bioss) overnight at $4{ }^{\circ} \mathrm{C}$, followed by the visualization with FITC-conjugated secondary antibody for $60 \mathrm{~min}$. The cells were counterstained 
with 4', 6-Diamidino-2-phenylindole (DAPI) for $5 \mathrm{~min}$ at room temperature in the dark. Images were collected and captured by confocal laser scanning microscopy (Zeiss LSM 880).

\section{$\mathrm{Mn}^{2+}-$ Phos-tag SDS-PAGE}

Phosphate-affinity/ $\mathrm{Mn}^{2+}$-Phos-tag SDS-PAGE has been described previously [29]. Briefly, dephosphorylated samples were prepared using cell lysate, $\mathrm{MgCl}_{2}$ and alkaline phosphatase (AP, Thermo Scientific, Waltham, MA, USA). After being incubated at $37^{\circ} \mathrm{C}$ for $12 \mathrm{~h}$, the dephosphorylated samples were mixed with $100 \mu \mathrm{l}$ of $3 \times$ SDSPAGE loading buffer. For $\mathrm{Mn}^{2+}$-Phos-tag SDS-PAGE, except for conventional reagents, the separating gel comprised acrylamide-pendant Phos-tag ligand and $\mathrm{MnCl}_{2}$. Before being transferred to nitrocellulose membrane, the gel of $\mathrm{Mn}^{2+}$-Phos-tag SDS-PAGE electrophoresis was softly rinsed with EDTA for $10 \mathrm{~min}$. The following steps were consistent with conventional western blotting described above.

\section{Dual luciferase reporter assay}

Luciferase assays were performed according to the manufacturer's instruction. Briefly, E-cadherin promoter was subcloned into pGL3-Basic luciferase expression vector (Genepharma). HeLa and SiHa cells were plated into 12well plates (Corning Incorporated), and each cell was transiently co-transfected with appropriate pcDNA3.1 plasmids together with luciferase plasmids using the XtremeGENE HP DNA Transfection Reagent (Roche). After $24 \mathrm{~h}$ transfection, cell lysates were harvested, and then luciferase activities were measured by the Dual-Luciferase Reporter System (Promega, Fitchburg, WI, USA) on a luminometer (Lumat LB 9507, EG\&G Berthold, Bad Wildbad, Germany). Firefly luciferase activities were normalized to the activities of Renilla luciferase control. The experiment was repeated three times.

\section{Xenograft mouse metastatic model}

Twelve female 6-week-old BALB/cA-node mice were purchased from Beijing Huafukang Bioscience (Beijing, China). Stable HeLa cells (LV-PAK5 and LV-Ctrl) were concentrated to $2 \times 10^{6} / 100 \mu \mathrm{l}$ PBS and injected into mice via the lateral tail vein. After 5 weeks, all mice were euthanized and lungs were then excised and photographed. The number of metastatic tumors per lung and its weight were counted and recorded. Finally, the lung tissues were harvested, embedded, fixed, and prepared for H\&E and IHC staining and western blotting.

\section{Statistical analysis}

All statistical analyses were determined using the SPSS version 17.0 (SPSS Inc., Chicago, IL, USA). Quantitative data were presented as means \pm SD. Statistical significance of Student's $t$-test was used for two-group comparisons. The $\chi^{2}$ or Fisher's exact test was applied to analyze the correlation between PAK5 expression and the clinicopathological parameters of CC patients. Survival analysis was estimated by the Kaplan-Meier method and the logrank test. $P<0.05$ was considered significant.

\section{Results}

\section{Elevated expression of PAK5 is correlated with the clinicopathological features of CC}

Western blotting results revealed that the expression of PAK5 was significantly up-regulated in diverse CC cells including SiHa, CaSki, C33A, MS751, and HeLa, as compared with NCECs (Fig. 1a, $P<0.05$ ). To further explore the correlation between PAK5 expression and CC progression, we conducted IHC staining in cervical specimens of 70 normal cervical tissues, 64 CINs and $163 \mathrm{CCs}$ (Fig. 1b, c). Tissue specimens were classified as low (IRS: 0-4) and high (IRS: 6-12) PAK5 expression via quantitative analysis of protein staining. PAK5 increased significantly with malignant progression of cervical tissues (Fig. 1b, d, $P<0.05$ ). High expression of PAK5 was observed in 98 of $163(60.1 \%)$ CC tissues, 21 of 64 (32.8\%) CINs and 0 of $70(0.0 \%)$ normal cervical tissues (Table 1$)$. These results suggested that PAK5 expression was upregulated in both CC tissues and cells.

The clinical relationship between PAK5 expression and clinicopathological parameters in $\mathrm{CC}$ was further analyzed to explore the importance of PAK5 expression. Statistical analysis suggested that high level of PAK5 was strongly correlated with some clinicopathological parameters of CC (Table 1), including high-risk HPV infection $(P=0.001)$, FIGO Stage $(P=0.003)$, LNM $(P=0.009)$, and recurrence $(P=0.039)$, whereas we did not find the compelling correlations of PAK5 expression with patient's age, histological type, tumor size, pathological grade, type of tumor growth, vaginal involvement, parametrial infiltration in CC.

To further understand the impact of PAK5 on clinical outcome of CC patients, Kaplan-Meier survival analysis and the log-rank test were performed based on expression level of PAK5. Our results indicated that PAK5 overexpression negatively correlated with five-year overall survival rate (Fig. 1e, $P<0.05$ ), which suggested that PAK5 might serve as a prognostic marker for $\mathrm{CC}$ patients. 
a

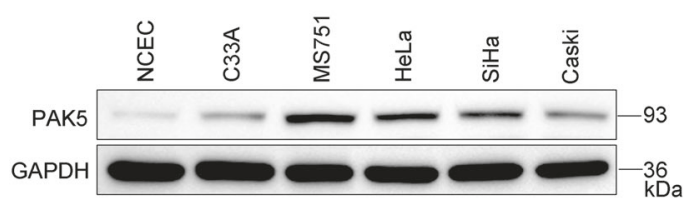

b
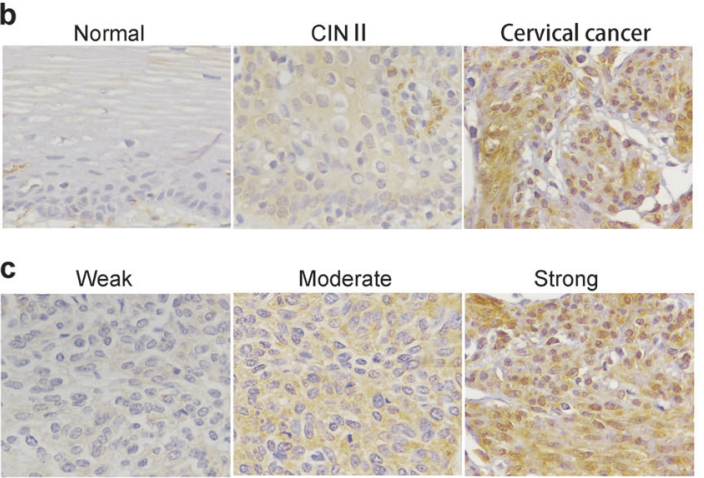

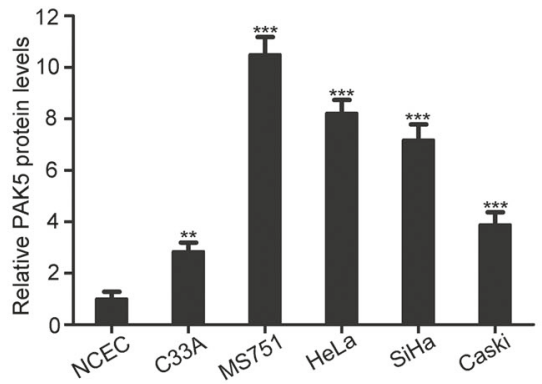

d

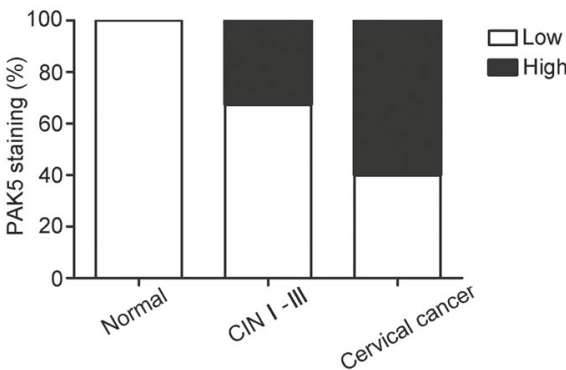

e

e Overall survival

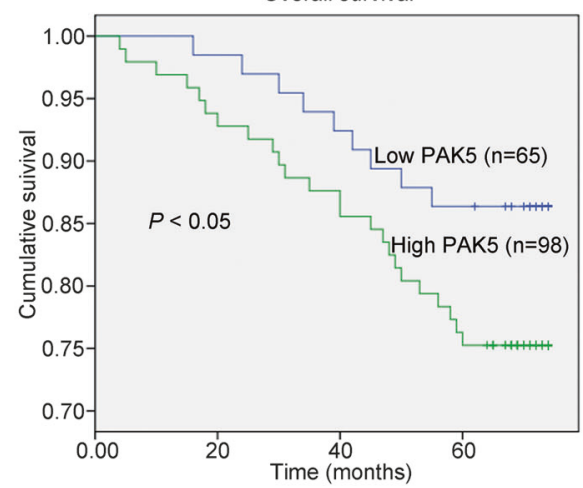

Fig. 1 Expression of PAK5 is up-regulated in CC cells and tissues and associated with 5-year overall survival in $\mathrm{CC}$ patients. a Protein expression of PAK5 in normal NCECs and human CC cells (SiHa, CaSki, C33A, MS751, HeLa) determined by western blotting. b IHC assay of PAK5 protein expression in normal cervical tissues, CIN II tissues and CC tissues. Original magnifications, $\times 400$ for b. c Representative images of IHC staining for PAK5 in CC tissues. Original

\section{The effects of PAK5 on proliferation of CC cells}

The above results showed that increased PAK5 expression is associated with malignant progression and an unfavorable prognosis of $\mathrm{CC}$. We thus wanted to determine whether overexpression of PAK5 promotes the growth of $\mathrm{CC}$ cells in vitro. HeLa and SiHa cells transfected with PAK5 plasmid were used for proliferation assay. Results from CCK-8 assay suggested that enforced PAK5 markedly accelerated cellular growth in both $\mathrm{HeLa}$ and $\mathrm{SiHa}$ cells (Fig. 2a), compared with the vector. Inversely, inhibiting the endogenous expression of PAK5 by siRNA remarkably suppressed proliferation of $\mathrm{HeLa}$ and $\mathrm{SiHa}$ cells in comparison with siCtrl (Fig. 2b). Clone forming magnifications, $\times 400$ for c. d PAK5 expression increased progressively with malignant progression of cervical tissues $(P<0.05)$. e Kaplan-Meier survival analysis of 163 cervical patients with high or low PAK5 expression $(P<0.05, \log$-rank test). **, $P<0.01$; ***, $P<$ 0.001. NCECs normal cervical epithelial cells, GAPDH glyceraldehyde-3-phosphate dehydrogenase, $C C$ cervical cancer, $C I N$ II cervical intraepithelial neoplasia, IHC immunohistochemistry

assays were then performed to validate the effect of PAK5 on the malignant growth of CC cells. As expected, the colony forming efficiency of HeLa and $\mathrm{SiHa}$ cells with PAK5 overexpression was significantly more than that in vector cells (Fig. 2c). Conversely, rate of clone formation $\mathrm{HeLa}$ and $\mathrm{SiHa}$ cells decreased upon endogenous PAK5 knockdown (Fig. 2d). These findings indicated that PAK5 potentiated CC cell proliferation and survival ability.

\section{The effects of PAK5 on migration and invasion of CC cells}

Given that there are significant correlations between increased PAK5 expression and aggressive features in 
Table 1 The correlation between PAK5 expression and clinicopathologic characteristics in IHC analysis

\begin{tabular}{|c|c|c|c|c|}
\hline \multirow[t]{2}{*}{ Variables } & \multirow{2}{*}{$\begin{array}{l}\text { Number } \\
(n=297)\end{array}$} & \multicolumn{3}{|c|}{ PAK5 expression } \\
\hline & & Low $(\%)$ & High (\%) & $P$-value \\
\hline Diagnostic category & & & & $<.001$ \\
\hline Normal & 70 & $70(100)$ & $0(0.0)$ & \\
\hline CIN II-III & 64 & $43(67.2)$ & $21(32.8)$ & \\
\hline Cervical cancer & 163 & $65(39.9)$ & $98(60.1)$ & \\
\hline Age (years) & & & & 0.735 \\
\hline$<55$ & 118 & $48(40.7)$ & $70(59.3)$ & \\
\hline$\geq 55$ & 45 & $17(37.8)$ & $28(62.2)$ & \\
\hline High-risk HPV infection & & & & 0.001 \\
\hline Yes & 101 & $30(29.7)$ & $71(70.3)$ & \\
\hline No & 62 & $35(56.5)$ & $27(43.5)$ & \\
\hline Histological type & & & & $0.490^{\mathrm{a}}$ \\
\hline Squamous carcinoma & 136 & $52(38.2)$ & $84(61.8)$ & \\
\hline Adenocarinoma & 20 & $9(45.0)$ & $11(55.0)$ & \\
\hline Others & 7 & $4(57.1)$ & $3(42.9)$ & \\
\hline FIGO Stage & & & & 0.003 \\
\hline I & 102 & $50(49.0)$ & $52(51.0)$ & \\
\hline II & 50 & $14(28.0)$ & $36(72.0)$ & \\
\hline III & 11 & $1(9.1)$ & $10(90.9)$ & \\
\hline Tumor size $(\mathrm{cm})$ & & & & 0.670 \\
\hline$\leq 4$ & 106 & $41(38.7)$ & $65(61.3)$ & \\
\hline$>4$ & 57 & $24(42.1)$ & $33(57.9)$ & \\
\hline Pathological grade & & & & 0.121 \\
\hline G1 & 43 & $22(51.2)$ & $21(48.8)$ & \\
\hline G2 & 79 & $31(39.2)$ & $48(60.8)$ & \\
\hline G3 & 41 & $12(29.3)$ & $29(70.7)$ & \\
\hline Types of tumor growth & & & & 0.852 \\
\hline Exophytic & 82 & $33(40.2)$ & $49(59.8)$ & \\
\hline Endophytic & 45 & $19(42.2)$ & $26(57.8)$ & \\
\hline Ulcerative & 36 & $13(36.1)$ & $23(63.9)$ & \\
\hline Vaginal involvement & & & & 0.615 \\
\hline Yes & 28 & $12(42.9)$ & $16(57.1)$ & \\
\hline No & 135 & $51(37.8)$ & $84(62.2)$ & \\
\hline Parametrial infiltration & & & & 0.282 \\
\hline Yes & 38 & $18(47.4)$ & $20(52.6)$ & \\
\hline No & 125 & 47 (37.6) & $78(62.4)$ & \\
\hline Lymph node metastases & & & & 0.009 \\
\hline Yes & 60 & $16(26.7)$ & $44(73.3)$ & \\
\hline No & 103 & 49 (47.6) & 54 (52.4) & \\
\hline Recurrence & & & & 0.039 \\
\hline Yes & 24 & $5(20.8)$ & 19 (70.9) & \\
\hline No & 139 & $60(43.2)$ & 79 (56.8) & \\
\hline
\end{tabular}

$C I N$ cervical intraepithelial neoplasia, FIGO the International Federation of Gynecology and Obstetrics, LNM lymph node metastasis

${ }^{a}$ Fisher's exact test

CC, which indicates that PAK5 facilitates tumor progression and transferring of CC. It is well-accepted acknowledged that malignant cells are characterized by possessing the capabilities and properties of adhesion and invasion. Hence, we assessed the effect of PAK5 on motility of CC cells. Wound-healing assays were utilized to examine the effect of PAK5 on cell migration. Our results showed that overexpression of PAK5 increased the capacity for $\mathrm{HeLa}$ and $\mathrm{SiHa}$ cell motility. HeLa and $\mathrm{SiHa}$ cells over-expressing PAK5 led to the faster closing of scratch wound compared with controls (Fig. 2e). Similarly, the wound filling was obviously retarded in HeLa and SiHa cells with siPAK5 (Fig. 2f). Next, quantification analysis through transwell assays showed that enforced expression of PAK5 dramatically enhanced the migration and invasion compared with negative control in both HeLa and SiHa cells (Fig. 2g). Knockdown of PAK5 effectively reduced the number of invaded cells in these two cell lines (Fig. 2h). Overall, these results suggested that PAK5 promotes the migration and invasion in CC cells in vitro.

\section{PAK5 phosphorylates SATB1 on serine 47}

It is reported that PAK5 could promotes the tumorigenic features of tumor cells through regulation transcription factor $[16,17]$. Since SATB1 is characterized by regulating various gene transcriptions, we wondered whether there are potential regulation mechanisms between PAK5 and SATB1. Western blotting results showed that increased PAK5 had no significant effect on the total SATB1 expression (Fig. 3a). The $\mathrm{Mn}^{2+}$-Phos-tag SDS-PAGE assays confirmed that PAK5 led to the upregulation of phosphorylated SATB1 in HeLa cells, which could be reversed by AP that preserves protein samples in the forms of non-phosphorylation (Fig. 3b). To further determine specific PAK5 phosphorylation site in SATB1, we calculated and predicted three possible phosphorylation sites (Ser47, Ser451, and Ser557) of SATB1 according to the principles and guidelines of PAKs phosphorylating substrates [30]. Three single-site mutation plasmids (described Ser47A, Ser451A and Ser557A) which were derived from candidate phosphorylation sites replaced by alanine were, respectively, co-transfected with PAK5 plasmids into HeLa cells. The results of $\mathrm{Mn}^{2+}$-Phos-tag SDS-PAGE assay showed that Ser47A (Ser47 to alanine) abrogated the phosphorylated status of SATB1 while accompanying with the elevation of unphosphorylated SATB1 in HeLa cells, while other mutations did not (Fig. 3c, d), suggesting that SATB1 Ser47 might be the major phosphorylation site by PAK5. Consistently, the observations from immunofluorescence staining found that the phospho-SATB1 Ser47 signal (red) that predominantly occurred in the nucleus was strikingly enhanced in $\mathrm{HeLa}$ and $\mathrm{SiHa}$ cells overexpressing PAK5 (Fig. 3e), which fully validated that PAK5 increased the expression of phospho-SATB1 in CC cells. Collectively, SATB1 is a phosphorylated substrate of PAK5. 

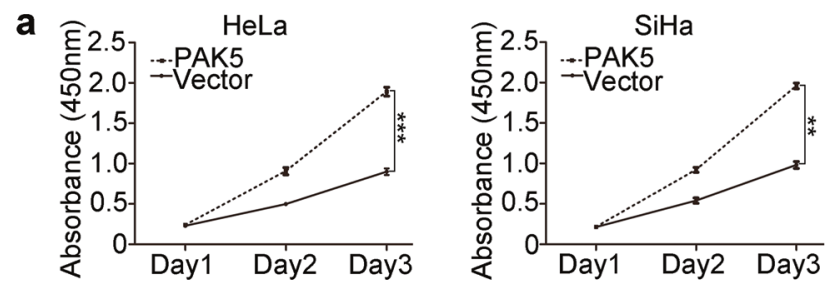

C

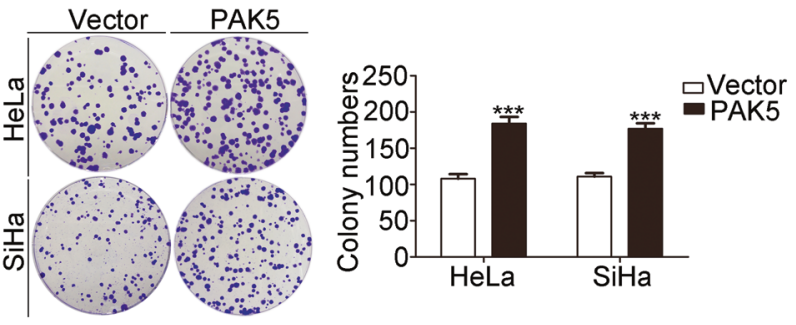

e
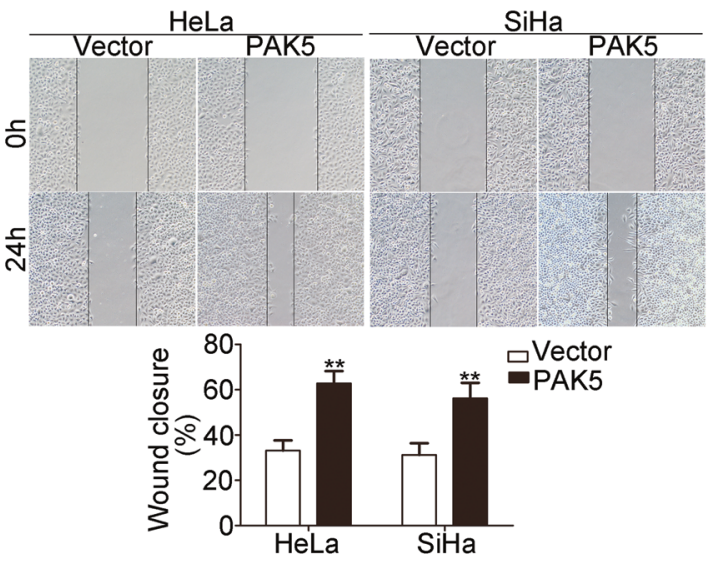

g
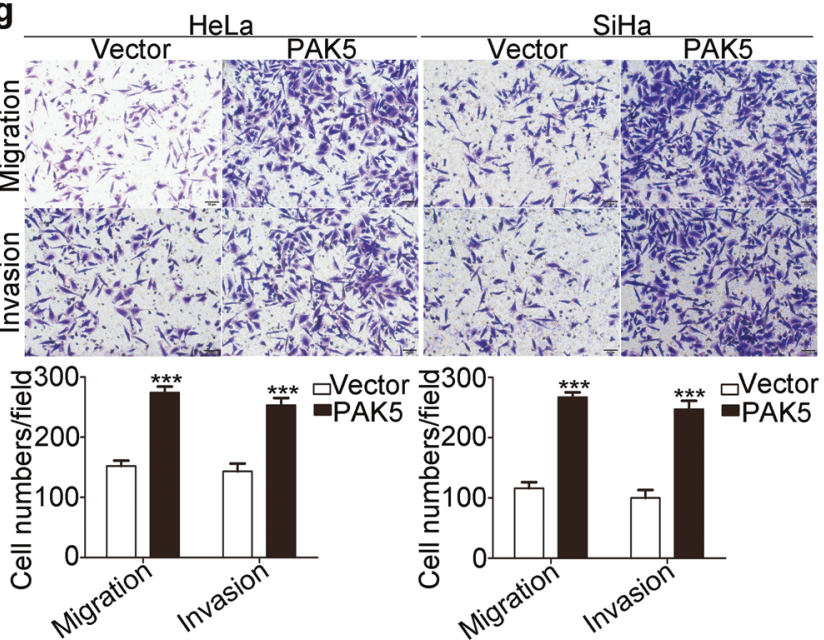

Fig. 2 PAK5 promotes proliferation, migration and invasion of $\mathrm{CC}$ cells in vitro. a, b CCK-8 assays were performed to determine the effects of PAK5 overexpression and knockdown on the proliferation of HeLa and SiHa cells. c, d The effects of PAK5 overexpression and knockdown on the clone formation of HeLa and SiHa cells. e, f The HeLa and SiHa cell motilities were measured through testing the wound closure after PAK5 overexpression and knockdown in HeLa
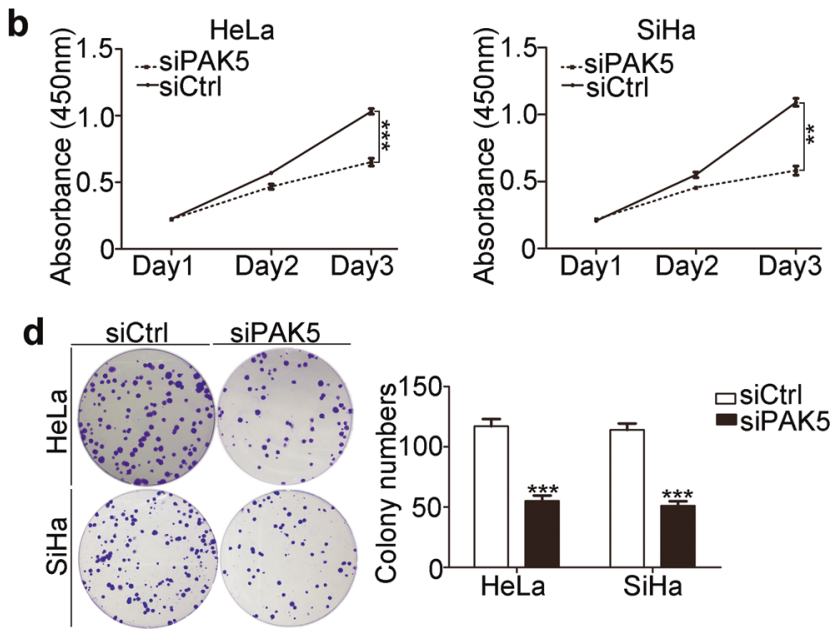

f
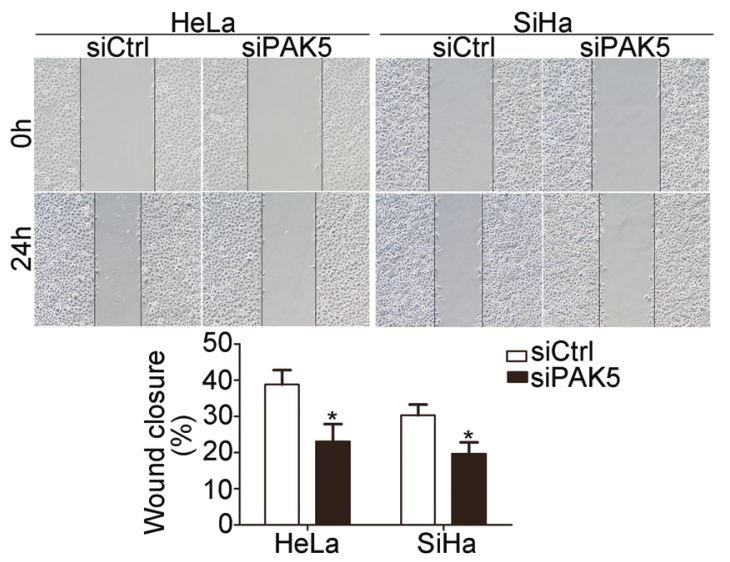

h

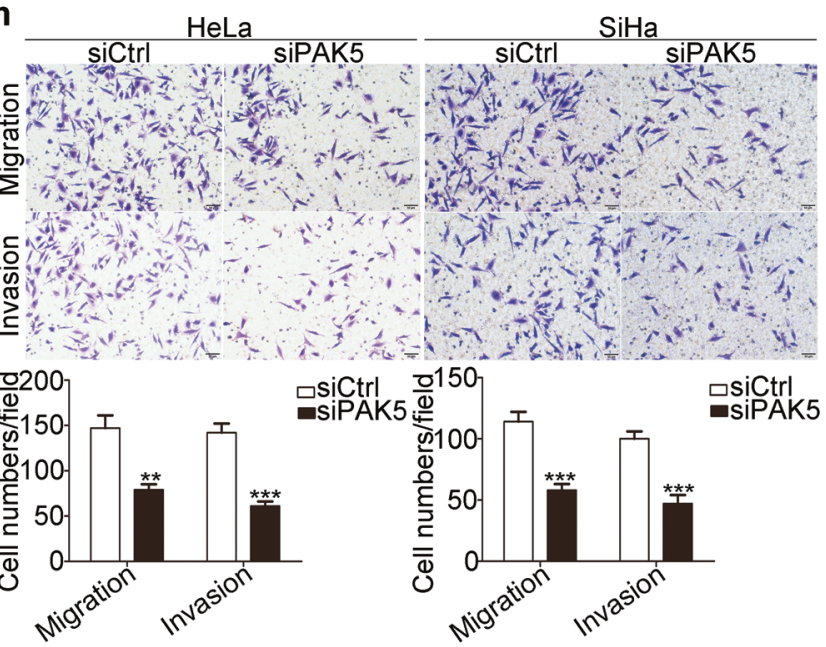

and SiHa cells, respectively. Original magnifications, $\times 400$ for e and $\mathrm{f}$. $\mathbf{g}, \mathbf{h}$ Transwell assays were used to detect the migration and invasion abilities after PAK5 overexpression and knockdown in HeLa and $\mathrm{SiHa}$ cells, respectively. Scale bar, $100 \mu \mathrm{m}$ for $\mathrm{g}$ and $\mathrm{h}$. Data are showed as mean $\pm \mathrm{SD}$ for three independent experiments. *, $P<0.05$; **, $P<$ 0.01 ; ***, $P<0.001$. CCK-8 Cell Counting Kit-8, siCtrl siRNA control, siPAK5 siRNA PAK5 
a

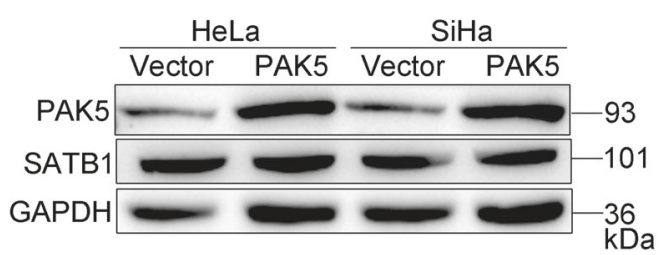

b

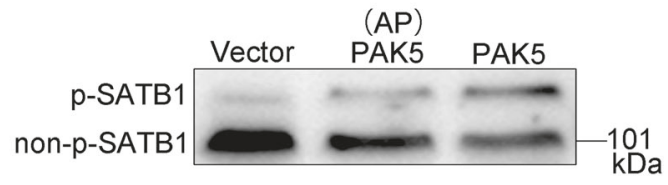

C

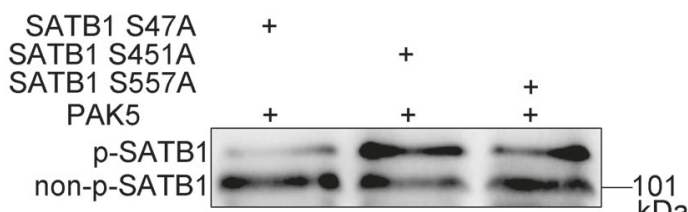

d

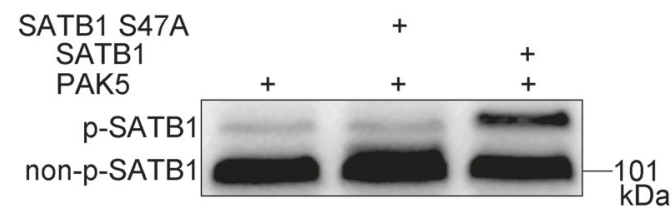

e

e

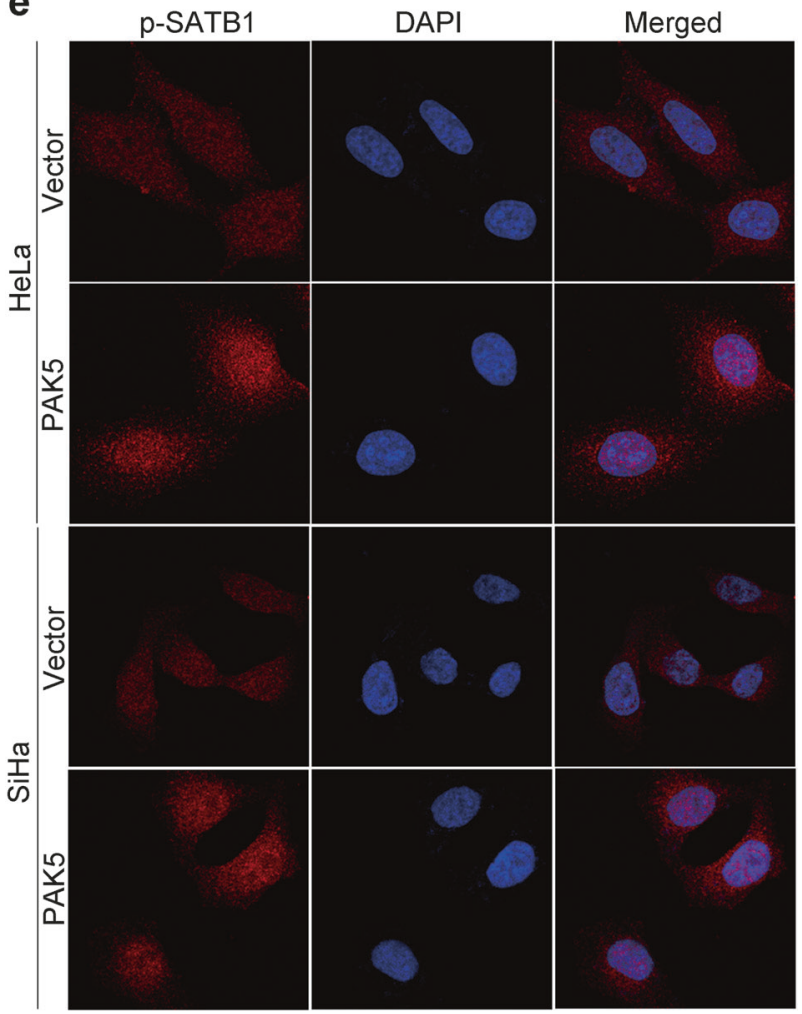

Merged

\section{Phosphorylation of SATB1 promotes the migration and invasion of CC cells}

To evaluate the potential function of phospho-SATB1 Ser47 in cell motility, we performed transwell assays in
Fig. 3 PAK5 phosphorylates SATB1 on Ser47. a Western blotting analysis of total SATB1 expression after PAK5 overexpression in $\mathrm{HeLa}$ and $\mathrm{SiHa}$ cells. b Lysates from HeLa cells transfected with control and PAK5 plasmids were used for $\mathrm{Mn}^{2+}$-Phos-tag SDS-PAGE assay with SATB1 antibodies. Lysates of middle lane were treated with AP. Shift bands (top) represented p-SATB1; bottom bands represented non-p-SATB1. c PAK5 plasmids and three single-site mutation (Ser47A, 451 A and 557 A) of SATB1 plasmids were respectively co-transfected into HeLa cells and lysates were subjected to $\mathrm{Mn}^{2+}$-Phos-tag SDS-PAGE assay to determine the specific phosphorylation site of SATB1 by PAK5. d PAK5 plasmids were respectively co-transfected with SATB1 and SATB1 Ser47A plasmids into HeLa cells to confirm the phosphorylation of SATB1 on Ser47 by PAK5. e Immunofluorescence staining of p-SATB1 Ser47 (red signal) was analyzed by confocal microscopy and the change of red fluorescence signal mainly occurred in the nucleus (blue signal) of HeLa and $\mathrm{SiHa}$ cells after overexpressing PAK5. Original magnifications, $\times 400$ for e. $G A P D H$ glyceraldehyde-3-phosphate dehydrogenase, $A P$ alkaline phosphatase, p-SATB1 phosphorylated SATB1, non-p-SATB1 non-phosphorylation SATB1, DAPI 4',6-diamidino-2-phenylindole

HeLa and SiHa cells. Up-regulation of wildtype (WT) SATB1 markedly strengthened the migration and invasion ability of CC cells compared with vector cells (Fig. 4a, b), whereas this was reversed and abated in cells transfected with SATB1 Ser47A (Fig. 4a, b). EMT is implicated in CC progression and metastasis $[4,5]$, and loss of the epithelial phenotype E-cadherin is a vital hallmark of EMT. We next elucidated the transcriptional regulation of PAK5 kinase on E-cadherin gene via luciferase reporter constructs. As shown in Fig. 4c, PAK5 overexpression significantly inhibited the transcriptional activity of E-cadherin in HeLa and SiHa cells. In addition, it was WT SATB1 rather than SATB1 Ser47A that notably inhibited the transcriptional stimulation of E-cadherin promoter activity in HeLa and $\mathrm{SiHa}$ cells. This observation confirmed that phosphorylation of SATB1 on Ser47 by PAK5 repressed the E-cadherin expression at the transcriptional level in CC cells. All the data suggested that PAK5 is an upstream signal molecule of SATB1 and induces migration and invasion of CC cells.

\section{PAK5-mediated STAB1 phosphorylation contributes to the alternation of EMT markers in CC cells}

As an oncogene in tumorigenesis, PAK5 has been reported to play a decisive role in promoting tumor progression and metastasizes [12, 16, 17, 31, 32]. We next determined the possible roles of SATB1 in PAK5-induced migration and invasion of CC cells. Western blotting showed that increased PAK5 enhanced the expressions of N-cadherin, Fibronectin, Slug, Twist, and Vimentin and decreased the expression of E-cadherin and ZO-1. Silencing endogenous SATB1 by siSATB1 abolished PAK5-induced changes in E-cadherin, ZO-1, N-cadherin, Fibronectin, Slug, Twist and Vimentin in HeLa cells (Fig. 4d). Meanwhile, PAK5 knockdown resulted in the up-regulation of E-cadherin and 
Fig. 4 PAK5-mediated phosphorylation promotes EMT in cervical cancer cells. a, b Effects of SATB1 and SATB1 Ser47A on the migration and invasion ability in HeLa and SiHa cells. Scale bar, $100 \mu \mathrm{m}$ for a and b. c HeLa and $\mathrm{SiHa}$ cells were transfected with pGL3-E, together with the indicated expression plasmids for Dual luciferase reporter assays. d Effects of SATB1 knockdown on EMT markers were analyzed by western blotting in HeLa cells overexpressing PAK5. e Effects of SATB1 overexpression on EMT markers in HeLa cells silencing PAK5. Data are showed as mean \pm SD for three independent experiments. **, $P<0.01$; ***, $P<0.001$. pGL3E $p G L 3$-E-cadherin promoter, siCtrl siRNA control, SiPAK5 siRNA PAK5, ns not significant, GAPDH glyceraldehyde-3-phosphate dehydrogenase a
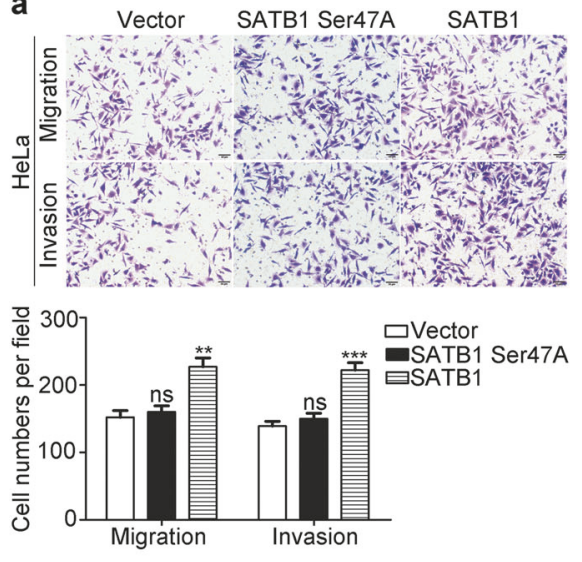

b

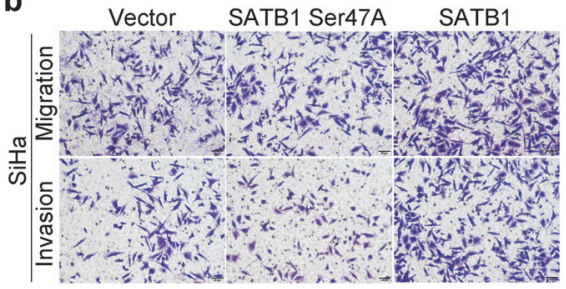

C

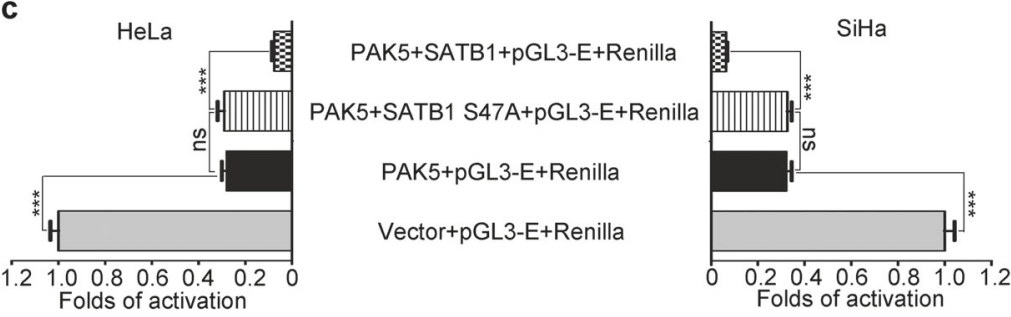

d

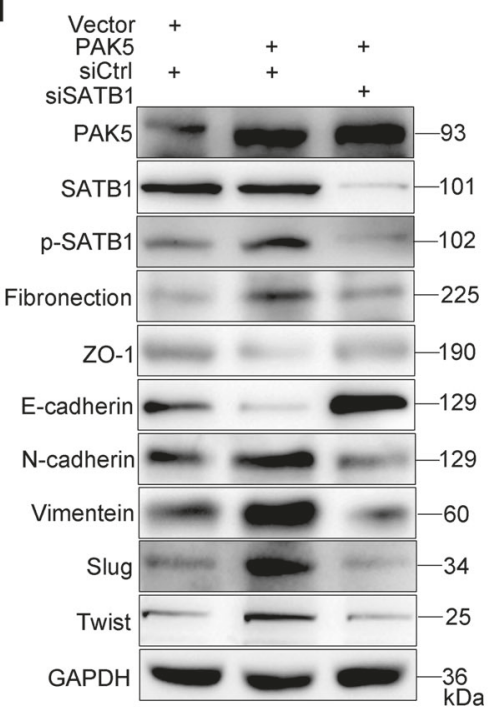

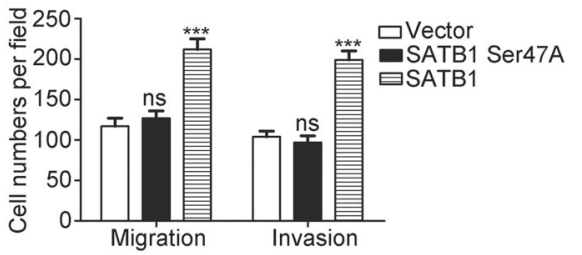

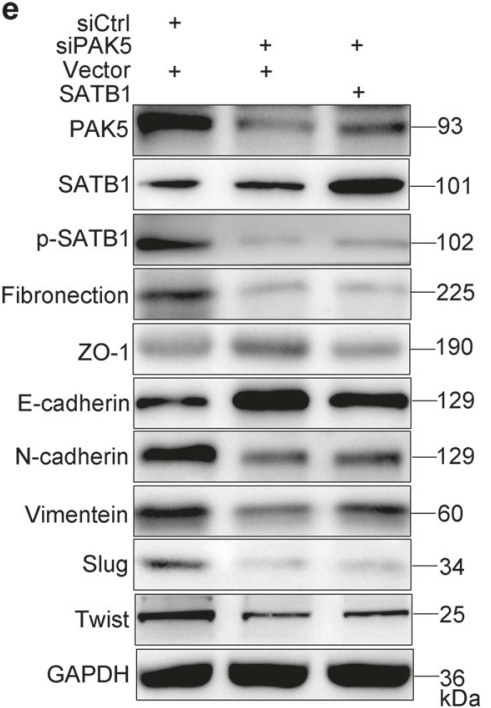

ZO-1 and the down-regulaton of N-cadherin, Fibronectin, Slug, Twist and Vimentin in HeLa cells, on this foundation, those EMT markers did not alter significantly after overexpressing SATB1 (Fig. 4e). These data were consistent with the results of the transwell assays displayed in Fig. $4 \mathrm{a}-\mathrm{c}$. Taken together, these results indicated that SATB1 works as a physiological substrate of PAK5 to promote EMT in CC cells.

\section{PAK5 promotes CC metastasis in vivo}

To further determine whether PAK5 promotes lung colonization of disseminated $\mathrm{CC}$ cells in vivo, we developed metastasis models of murine xenograft. HeLa cells were transfected by lentivirus encoding PAK5. Next, equal numbers of LV-PAK5 and LV-Ctrl HeLa cells were intravenously injected into two groups of 6-week-old BALB/cAnode mice each via tail respectively. Five weeks after implantation, all mice were sacrificed, and the metastatic nodules on the lung surfaces were recorded. There was a higher incidence of lung metastasis in mice inoculated with LV-PAK5 group compared with LV-Ctrl group. Enforced expression of PAK5 promoted HeLa cells colonization to the lung and increased the numbers of metastasis nodules in mice (Fig. 5a, b, $P<0.05$ ). Additionally, the lung weights in LV-PAK5 group were higher than that in LV-Ctrl group 
a

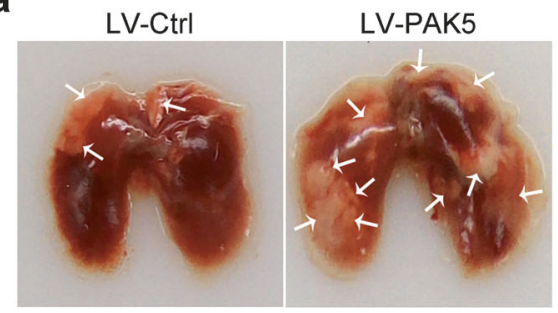

b

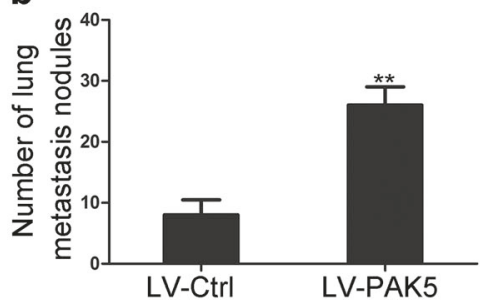

C

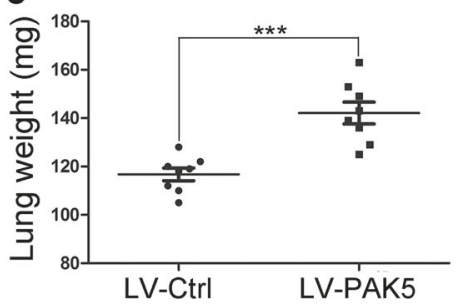

d

e

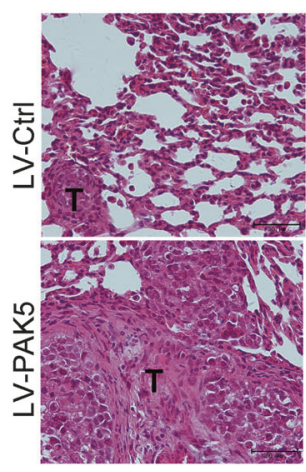

PAK5

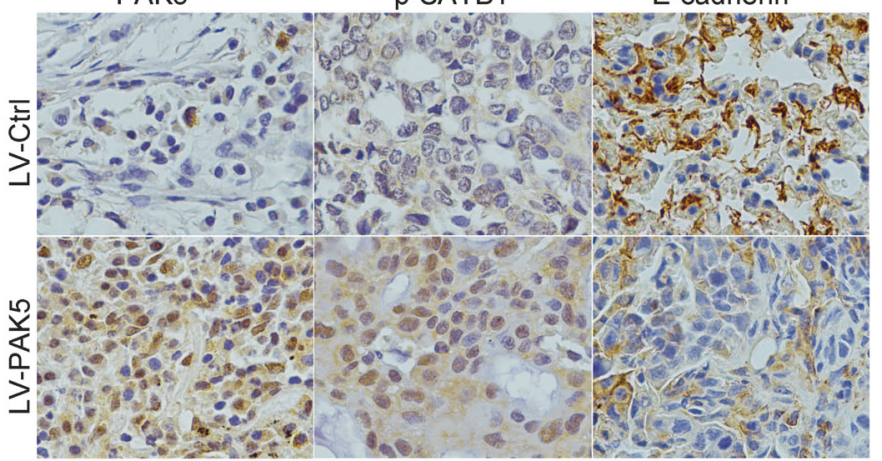

f

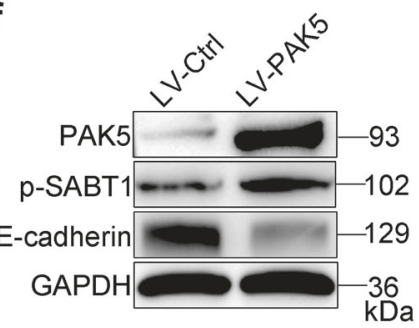

Fig. 5 PAK5 promotes CC cell metastasis in vivo. a Lungs originated from mice injected with lentivirus-mediated HeLa cells. The white arrow marked metastatic nodules. b Numbers of lung metastasis nodules from each mouse were counted. c Weights of lung were counted. d H\&E staining of lung sections. Scale bar, 100 $\mu \mathrm{m}$ for d. e Representative images of IHC staining for PAK5, p-SATB1 Ser47 and E-cadherin in lung tissues. Original magnifications, $\times 400$ for e. f Western blotting detected the protein expressions of PAK5, phospho-SATB1 Ser47 and E-cadherin in lung tissues. Data are showed as mean \pm SD. $* *, P<0.01$; ***, $P<0.001$. LV-Ctrl controllentivirus, $L V$-PAK5 PAK5-lentivirus, $p$-SATB1 Ser47 phosphorylated SATB1 Ser47, $H \& E$ hematoxylin-eosin staining, $I H C$ immunohistochemistry, GAPDH glyceraldehyde-3-phosphate dehydrogenase

PAKs on downstream signaling cascades result in phenotypic changes related to tumorigenesis and progression $[8,36]$. Previous studies suggested that PAK5 promotes the invasion and metastasis of breast cancer and glioma cells via regulating Egr1/MMP2 signal axis [16, 17]. Gong et al confirmed that the high expression level of PAK5 is significantly associated with tumor progression in colon cancer and might act as a prognostic factor of worse outcome [32]. Apart from tumorigenesis and progression, PAK5 exerts considerable influence on attenuating chemosensitivity of anti-cancer drugs [13, 37], such as cisplatin in hepatocellular carcinoma, paclitaxel in ovarian cancer and gemcitabine in pancreatic cancer. The existing researches indicate that the roles of PAK5 in tumor development and progression are mainly embodied in the followings: promotion of tumor cells migration, diffusion and anti-apoptosis and accelerating of tumor cells proliferation. However, the effects of PAK5 on CC tumorigenesis and metastasis have never been reported by others.

In the present study, we investigated PAK5 expression in cervical tissues and CC cells. The protein level of PAK5 was up-regulated in $\mathrm{CC}$ cells compared with NCECs. Strong PAK5 staining is detected in CC tissues, whereas absent or low expression is showed in most normal cervical tissues and CIN, which indicates that PAK5 may display [35]. The effects of aberrant expression or activation of 
vital role in the carcinogenesis and progression of $\mathrm{CC}$. We further evaluated the correlations between PAK5 expression and clinicopathological features as well as prognostic survival in CC. Our findings showed that elevated PAK5 expression was significantly associated with the high-risk HPV infection, histological type, FIGO stage, LNM and recurrence. High levels of PAK5 protein strongly reduced the overall survival among CC patients and PAK5 might therefore serve as a prognostic parameter for CC. Subsequently, we investigated the roles of PAK5 in CC cells by specifically interfering or overexpressing PAK5. PAK5 overexpression conferred on cells tumorigenic properties and contributed to proliferation, migration and invasion of $\mathrm{CC}$ cells in vitro, PAK5 knockdown resulted in a reverse trend. These data evidence supported that PAK5 is involved in tumorigenesis and progression of $\mathrm{CC}$, which is consistent with previous studies to support cancer-promoting characters of PAK5 [15-17, 31, 32].

SATB1, a MAR-binding transcription factor, plays a vital role in reprograming chromatin architecture and gene regulation, and its changes are affecting many gene expressions [19, 20], with transcriptional activation or repression. This suggests that SATB1 upstream should have one or more mechanisms which affect its transcriptional activity. PAK5 signaling has been proved to modulate diverse transcription factors such as GATA1 [38], egr1 $[16,17]$, RAF1, and NF-kB-p65 [39, 40]. However, PAK5SATB1 signaling pathway in CC has yet to be determined. A growing number of studies have focused on the relationship between SATB1 expression and the occurrence and development of human cancers in the past decade $[22,23,25,41,42]$, and its biological functions in various tumors have been explored in detail. For example, Mir R et al reported that SATB1 reprograms tumor related genes to facilitate tumorigenesis and progression of colorectal cancer via Wnt/ $\beta$-catenin signaling [43]. Han $\mathrm{HJ}$ et al. revealed that SATB1 potentiates the invasive behavior and metastatic phenotype of breast cancer and serves as a novel biomarker for breast cancer progression and distant metastasis [25]. Beyond that, aberrant expression of SATB1 is also associated with pathological parameters and poorer outcome in solid tumors, such as cutaneous malignant melanoma [22], prostate cancer [23], nasopharyngeal carcinoma [24], and epithelial ovarian cancer [26]. In this paper, we specifically focused on exploring and understanding the mechanisms by which PAK5 governs SATB1 and affect the migration and invasion of CC cells.

Our western blotting results revealed that total SATB1 protein was unaltered upon PAK5 overexpression. It has been documented that SATB1 is directly phosphorylated by $\mathrm{PKC}$ at serine residue (s) via phosphorylation assays [44]. As an analog, PAK5 may phosphorylate SATB1. Our findings confirmed that SATB1 was a novel substrate protein of PAK5, and PAK5 primarily phosphorylated SATB1 on Ser47 in CC cells. PAK5 overexpression inhibited the level of E-cadherin and promoted migration and invasion in CC cells. Animal model of CC metastases confirmed that PAK5 enhanced lung metastases in vivo. It has been reported that PAK5 is characterized by remodeling cytoskeleton, somehow regulating cell mobility through modulating cytoskeleton shape [10]. PAK5-mediatd phosphorylation animates Raf-1 [39], which take part in the activation mechanism of Raf-1 and partly affects cell invasion and migration via ERK/MAPK pathway [10]. All these well documented that PAK5 may play essential roles in initiating the metastatic cascade of CC. Malignancy invasion and distant metastasis is a multi-factor, multi-step dynamic processes which are usually initiated by the EMT during which epithelial cells are subjected to morphological changes, loss of adhesion and gain the property of invasion and migration $[45,46]$. Transcription factor activation, such as Slug and Twist are the causative agents to suppress epithelial marker, E-cadherin and ZO-1, and increase mesenchymal markers, Fibronectin, Vimentin, and Ncadherin [45, 46]. Consistent with this, PAK5-mediated SATB1 phosphorylation led to the alteration of several EMT markers, including Snail, Slug, Twist and ZO-1, Fibronectin, Vimentin and N-cadherin, which induced cellular dispersion and metastatic cascade in CC. Metastasis models of PAK5 overexpression showed higher level of phospho-SATB1 Ser47 and lower level of E-cadherin. Those are also in line with the previous discoveries that PAK overexpression or hyperactivation is often responsible for triggering EMT event [47]. Overall, PAK5-mediated SATB1 phosphorylation contributed to the downregulation of E-cadherin, consequently decreased intercellular cohesion and induced motility and metastasis of CC cells.

Our research investigated the role of SATB1 in PAK5 inducing migration and invasion of $\mathrm{CC}$ cells. However, there still are some deficiencies in current studies, due to the complexity of mechanism related to SATB1 signaling in carcinogenesis. In recent years, SATB1 has been proved to be implicated in the occurrence and development of diverse tumors, whereas there is no unified explanation and exact conclusion on the roles of SATB1 in tumor. A few reports showed that SATB1 is low expressed or absent and is scarcely relevant to tumor progression in certain human tumors, such as colorectal cancer and lung cancer [48, 49]. $\mathrm{Han} \mathrm{HJ}$ et al. confirmed that overexpression of SATB1 has a poor prognosis and could serve as an independent prognostic factor [25]. Different from the above perspective, Iorns $\mathrm{E}$ et al. specifically proposed that SATB 1 cannot be used as a prognostic marker for breast cancer patients through statistic and analysis of 2058 cases [42]. Moreover, the co-expression of PAK5 and phosphorylated SATB1 and their correlations are still needed to the further testify in CC 
tissues. The effects of phosphorylated SATB1 on proliferation of $\mathrm{CC}$ cells are also uncertain. In this paper, we first reported that increased PAK5 is closely related to aggressive phenotype in $\mathrm{CC}$ and it promotes the adhesion, migration and invasion of $\mathrm{CC}$ cells via phosphorylating SATB1 on Ser47, which shed light on understanding PAK5 activity in CC pathophysiology.

\section{Conclusion}

In summary, our results provide an evidence for the emerging connections among PAK5, EMT markers and CC metastasis mediated by SATB1, despite some controversy concerning SATB1. PAK5 expression is increased in CC tissues and cell lines. High expression of PAK5 is significantly linked to the progression of CC and it could act as valid prognostic factor of CC. PAK5 induces EMT and enhances metastasis of CC by phosphorylating SATB1 on Ser47. Therefore, PAK5-SATB1 signals provide potential therapeutic avenues for therapeutic intervention in CC.

Acknowledgements This work was supported by the National Natural Science Foundation of China [No. 81572349], Jiangsu Provincial Medical Talent [ZDRCA2016055] and the Science and Technology Department of Jiangsu Province [BK20141149].

Author contributions F.C.H., Y.J.P. performed the experiments and wrote the paper; T.T.L. analyzed and data and partially participated in the experiments; J.M., D.S.P. designed and supervised the project.

\section{Compliance with ethical standards}

Conflict of interest The authors declare that they have no conflict of interest.

\section{References}

1. Jemal A, Bray F, Center MM, Ferlay J, Ward E, Forman D. Global cancer statistics. CA Cancer J Clin. 2011;61: 69-90.

2. Siegel R, Naishadham D, Jemal A. Cancer statistics, 2012. CA Cancer J Clin. 2012;62:10-29.

3. Siegel R, Desantis C, Jemal A. Colorectal cancer statistics, 2014. CA Cancer J Clin. 2014;64:104-17.

4. Qureshi R, Arora H, Rizvi MA. EMT in cervical cancer: its role in tumour progression and response to therapy. Cancer Lett. 2015;356:321-31.

5. Lee MY, Shen MR. Epithelial-mesenchymal transition in cervical carcinoma. Am J Transl Res. 2012;4:1-13.

6. Lee J, Song Y, Soh EY. Prognostic significance of the number of metastatic lymph nodes to stratify the risk of recurrence. World J Surg. 2014;38:858-62.

7. Shingleton HM, Jones WB, Russell A, Fremgen A, Chmiel JS, Ocwieja K, et al. Hysterectomy in invasive cervical cancer: a national patterns of care study of the American College of Surgeons. J Am Coll Surg. 1996;183:393-400.
8. Ye DZ, Field J. PAK signaling in cancer. Cell Logist. 2012;2:105-16.

9. Pandey A, Dan I, Kristiansen TZ, Watanabe NM, Voldby J, Kajikawa E, et al. Cloning and characterization of PAK5, a novel member of mammalian p21-activated kinase-II subfamily that is predominantly expressed in brain. Oncogene. 2002;21:3939-48.

10. Wen YY, Wang XX, Pei DS, Zheng JN. p21-Activated kinase 5: a pleiotropic kinase. Bioorg Med Chem Lett. 2013;23:6636-9.

11. Dan C, Nath N, Liberto M, Minden A. PAK5, a new brain-specific kinase, promotes neurite outgrowth in N1E-115 cells. Mol Cell Biol. 2002;22:567-77.

12. Zhu G, Li X, Guo B, Ke Q, Dong M, Li F. PAK5-mediated E47 phosphorylation promotes epithelial-mesenchymal transition and metastasis of colon cancer. Oncogene. 2016;35:1943-54.

13. Li D, Yao X, Zhang P. The overexpression of P21-activated kinase 5 (PAK5) promotes paclitaxel-chemoresistance of epithelial ovarian cancer. Mol Cell Biochem. 2013;383:191-9.

14. Han K, Zhou Y, Gan ZH, Qi WX, Zhang JJ, Fen T, et al. p21activated kinase 7 is an oncogene in human osteosarcoma. Cell Biol Int. 2014;38:1394-402.

15. Fang ZP, Jiang BG, Gu XF, Zhao B, Ge RL, Zhang FB. P21activated kinase 5 plays essential roles in the proliferation and tumorigenicity of human hepatocellular carcinoma. Acta Pharmacol Sin. 2014;35:82-8.

16. Wang XX, Cheng Q, Zhang SN, Qian HY, Wu JX, Tian H, et al. PAK5-Egr1-MMP2 signaling controls the migration and invasion in breast cancer cell. Tumour Biol. 2013;34:2721-9.

17. Han ZX, Wang XX, Zhang SN, Wu JX, Qian HY, Wen YY, et al. Downregulation of PAK5 inhibits glioma cell migration and invasion potentially through the PAK5-Egr1-MMP2 signaling pathway. Brain Tumor Pathol. 2014;31:234-41.

18. Liu J, Barnett A, Neufeld EJ, Dudley JP. Homeoproteins CDP and SATB1 interact: potential for tissue-specific regulation. Mol Cell Biol. 1999;19:4918-26.

19. Yasui D, Miyano M, Cai S, Varga-Weisz P, Kohwi-Shigematsu T. SATB1 targets chromatin remodelling to regulate genes over long distances. Nature. 2002;419:641-5.

20. Cai S, Lee CC, Kohwi-Shigematsu T. SATB1 packages densely looped, transcriptionally active chromatin for coordinated expression of cytokine genes. Nat Genet. 2006;38:1278-88.

21. Kouzarides T. Histone acetylases and deacetylases in cell proliferation. Curr Opin Genet Dev. 1999;9:40-8.

22. Chen H, Takahara M, Oba J, Xie L, Chiba T, Takeuchi S, et al. Clinicopathologic and prognostic significance of SATB1 in cutaneous malignant melanoma. J Dermatol Sci. 2011;64:39-44.

23. Shukla S, Sharma H, Abbas A, MacLennan GT, Fu P, Danielpour $\mathrm{D}$, et al. Upregulation of SATB1 is associated with prostate cancer aggressiveness and disease progression. PLoS ONE. 2013;8: e53527.

24. Shen Z, Zeng Y, Guo J, Wu Y, Jiang X, Ding R, et al. Overexpression of the special AT rich sequence binding protein 1 (SATB1) promotes the progression of nasopharyngeal carcinoma: association with EBV LMP-1 expression. J Transl Med. 2013;11:217.

25. Han HJ, Russo J, Kohwi Y, Kohwi-Shigematsu T. SATB1 reprogrammes gene expression to promote breast tumour growth and metastasis. Nature. 2008;452:187-93.

26. Nodin B, Hedner C, Uhlen M, Jirstrom K. Expression of the global regulator SATB1 is an independent factor of poor prognosis in high grade epithelial ovarian cancer. J Ovarian Res. 2012;5:24.

27. Guo M, Zhao X, Yuan X, Jiang J, Li P. MiR-let-7a inhibits cell proliferation, migration, and invasion by down-regulating PKM2 in cervical cancer. Oncotarget. 2017;8:28226-36.

28. Tian T, Li X, Hua Z, Ma J, Wu X, Liu Z, et al. S100A7 promotes the migration, invasion and metastasis of human cervical cancer 
cells through epithelial-mesenchymal transition. Oncotarget. 2017;8:24964-77.

29. Kinoshita E, Kinoshita-Kikuta E, Koike T. Separation and detection of large phosphoproteins using Phos-tag SDS-PAGE. Nat Protoc. 2009;4:1513-21.

30. Tuazon PT, Spanos WC, Gump EL, Monnig CA, Traugh JA. Determinants for substrate phosphorylation by $\mathrm{p} 21$-activated protein kinase (gamma-PAK). Biochemistry. 1997;36:16059-64.

31. Ismail AF, Oskay Halacli S, Babteen N, De Piano M, Martin TA, Jiang WG, et al. PAK5 mediates cell: cell adhesion integrity via interaction with E-cadherin in bladder cancer cells. Biochem J. 2017;474:1333-46.

32. Gong W, An Z, Wang Y, Pan X, Fang W, Jiang B, et al. P21activated kinase 5 is overexpressed during colorectal cancer progression and regulates colorectal carcinoma cell adhesion and migration. Int J Cancer. 2009;125:548-55.

33. Bokoch GM. Biology of the p21-activated kinases. Annu Rev Biochem. 2003;72:743-81.

34. Coleman N, Kissil J. Recent advances in the development of p21activated kinase inhibitors. Cell Logist. 2012;2:132-5.

35. Eswaran J, Soundararajan M, Knapp S. Targeting group II PAKs in cancer and metastasis. Cancer Metastasis Rev. 2009;28:209-17.

36. Molli PR, Li DQ, Murray BW, Rayala SK, Kumar R. PAK signaling in oncogenesis. Oncogene. 2009;28:2545-55.

37. Zhang DG, Zhang J, Mao LL, Wu JX, Cao WJ, Zheng JN, et al. p21-Activated kinase 5 affects cisplatin-induced apoptosis and proliferation in hepatocellular carcinoma cells. Tumour Biol. 2015;36:3685-91.

38. Li Y, Ke Q, Shao Y, Zhu G, Li Y, Geng N, et al. GATA1 induces epithelial-mesenchymal transition in breast cancer cells through PAK5 oncogenic signaling. Oncotarget. 2015;6:4345-56.

39. Wu X, Carr HS, Dan I, Ruvolo PP, Frost JA. p21 activated kinase 5 activates Raf-1 and targets it to mitochondria. J Cell Biochem. 2008;105:167-75.
40. Zhang YC, Huo FC, Wei LL, Gong CC, Pan YJ, Mou J, et al. PAK5-mediated phosphorylation and nuclear translocation of NFkappaB-p65 promotes breast cancer cell proliferation in vitro and in vivo. J Exp Clin Cancer Res. 2017;36:146.

41. Kohwi-Shigematsu T, Poterlowicz K, Ordinario E, Han HJ, Botchkarev VA, Kohwi Y. Genome organizing function of SATB1 in tumor progression. Semin Cancer Biol. 2013;23:72-9.

42. Iorns E, Hnatyszyn HJ, Seo P, Clarke J, Ward T, Lippman M. The role of SATB1 in breast cancer pathogenesis. J Natl Cancer Inst. 2010;102:1284-96.

43. Mir R, Pradhan SJ, Patil P, Mulherkar R, Galande S. Wnt/betacatenin signaling regulated SATB1 promotes colorectal cancer tumorigenesis and progression. Oncogene. 2016;35:1679-91.

44. Pavan Kumar P, Purbey PK, Sinha CK, Notani D, Limaye A, Jayani RS, et al. Phosphorylation of SATB1, a global gene regulator, acts as a molecular switch regulating its transcriptional activity in vivo. Mol Cell. 2006;22:231-43.

45. Nieto MA, Huang RY, Jackson RA, Thiery JP. Emt: 2016. Cell . 2016;166:21-45.

46. Lamouille $\mathrm{S}$, Xu J, Derynck R. Molecular mechanisms of epithelial-mesenchymal transition. Nat Rev Mol Cell Biol. 2014;15:178-96.

47. Yang Z, Rayala S, Nguyen D, Vadlamudi RK, Chen S, Kumar R. Pak1 phosphorylation of snail, a master regulator of epithelial-tomesenchyme transition, modulates snail's subcellular localization and functions. Cancer Res. 2005;65:3179-84.

48. Al-Sohaily S, Henderson C, Selinger C, Pangon L, Segelov E, Kohonen-Corish MR, et al. Loss of special AT-rich sequencebinding protein 1 (SATB1) predicts poor survival in patients with colorectal cancer. Histopathology. 2014;65:155-63.

49. Selinger CI, Cooper WA, Al-Sohaily S, Mladenova DN, Pangon L, Kennedy CW, et al. Loss of special AT-rich binding protein 1 expression is a marker of poor survival in lung cancer. $\mathrm{J}$ Thorac Oncol. 2011;6:1179-89. 